\title{
Innovation policy analysis and decision making: a systems approach
}

\author{
$\underline{\text { E. Suprun }}^{\text {a, b, c }}{ }^{\text {, O. Sahin }}{ }^{\text {a, b, c, }}$, R.A. Stewart ${ }^{\text {a, b, c, }}{ }^{\text {K. Panuwatwanich }}{ }^{\text {d }}$ and Y. Shcherbachenko ${ }^{e}$ \\ ${ }^{a}$ Griffith School of Engineering, Griffith University, Queensland, Australia \\ ${ }^{b}$ Cities Research Institute, Griffith University, Queensland, Australia \\ ${ }^{c}$ GCCRP Griffith Systems Modelling Group, Griffith University, Queensland, Australia \\ ${ }^{d}$ School of Civil Engineering and Technology, Sirindhorn International Institute of Technology, Thammasat \\ University, Thailand \\ ${ }^{e}$ Capital Construction of the Belgorod Region Ltd, Belgorod, Russia \\ Email: e.suprun@griffith.edu.au
}

\begin{abstract}
The construction industry is one of the largest and most diverse of the sectors with continuous development. The momentum and impact of the industry's development is highly influenced by a complex system of different elements including innovation. However, the sector is relatively weak at all stages of the innovation process and the strength of collaboration among government, industry and academia is insufficient. It is generally accepted that construction companies invest less in new knowledge and process development as well as engage significantly less in innovation related activities than firms in other sectors. Hence, it is very important to control and manage the significant factors that affect success in innovation taking into account the complexity and the inherent dynamics of the construction innovation diffusion. By doing so, this study addresses the decision making process within the complex innovation process in the construction industry by employing a step-by-step modelling process consisting of a multi-stages analysis, stakeholder-based and modelling approaches. Construction is closely connected to the national social structure and is highly influenced by various institutional actors and interactions among components and, consequently, can be presented as a sectoral system. Hence, the overarching objective of the paper is to introduce a systems approach aiming to conceptualise and formulate an initial simulation model of a complex construction innovation system representing correct and continuous interactions between government, the construction industry and academia. Moreover, the research underpins future development of scenariogenerating modelling in order to reveal potential pathways to rational decision-making along with potential policy recommendations and various innovation planning strategies that improve construction innovation performance in the Russian Federation.
\end{abstract}

Innovation in the construction industry can take various forms and, as a result, is not well represented by official statistics. Therefore, active stakeholder engagement is required to develop appropriate metrics and build the foundations for such a dynamic model, given the level of complexity. As a part of participatory modelling, stakeholder engagement involves: (i) stakeholder identification and stakeholder analysis; (ii) questionnaire-based survey and face-to-face interviews; (iii) consultations with academic and industry professionals; (iv) opinion survey; and (v) facilitated expert workshops. In other words, involvement of stakeholders is an essential requirement given the multi-actor nature of the system under study and lack of data involved. The first research stage aims to identify the most significant barriers, enablers and strategies that most significantly affect construction innovation diffusion in Russia. The results suggest that the construction industry requires assistance and support from the government in order to endure existing impediments and to improve the current lacklustre rate of construction innovation. The next stage determines the degree of influence that the different system's components have on each other. Then, the structural analysis is performed using MICMAC (Cross-Impact Matrix Multiplication Applied to Classification) technique in order to generate the required information about interconnections between the key variables. This stage is effective in building a comprehensive conceptual model, followed by an ongoing dynamic model development, integrating both qualitative and quantitative variables. The model structure highlights that construction companies and academia representatives, along with decision-makers need to acknowledge innovation as a process of development and accumulate innovation capabilities in the whole construction innovation system in order to achieve the benefits of high-level innovation performance. One of the dynamic hypotheses describing the problem under study, centres on how the industry, academia and the government can collaborate to most effectively diffuse innovations throughout the industry.

Keywords: Systems modelling, stakeholder engagement, construction innovation system, decision making 


\section{INTRODUCTION}

It is generally accepted, that construction companies have limited openness to external knowledge and process development as a result of low levels of investment in new knowledge, which, subsequently, leads to relatively low levels of innovation capability and innovation performance. The innovation process in the construction sector is an inherently complex issue involving multiple actors and interactions in developing and implementing innovations (Ozorhon and Kutluhan, 2017; Seaden and Manseau, 2001; Suprun et al., 2016; Van Egmond, 2012).

According to the exploratory study previously conducted by the authors (Suprun and Stewart, 2015), the most significant obstacle to construction innovation diffusion in Russia is an inability of the government to build up a regulatory institutional framework that would encourage construction companies to be innovative. Moreover, significant problems remain in terms of economic and financial difficulties, lack of research support and weak R\&D collaboration along with multi-functional involvement in the innovation process. The widest gaps can be found in sector R\&D expenditures as a share of sector revenue, and in the rate of current industry and academia collaboration. Therefore, it is important to present the problems of the innovation process in the industry from the systemic construction industry-wide perspective in order to promote the common interests of all actors and, as a result, to improve innovation performance. The innovation system approach aims

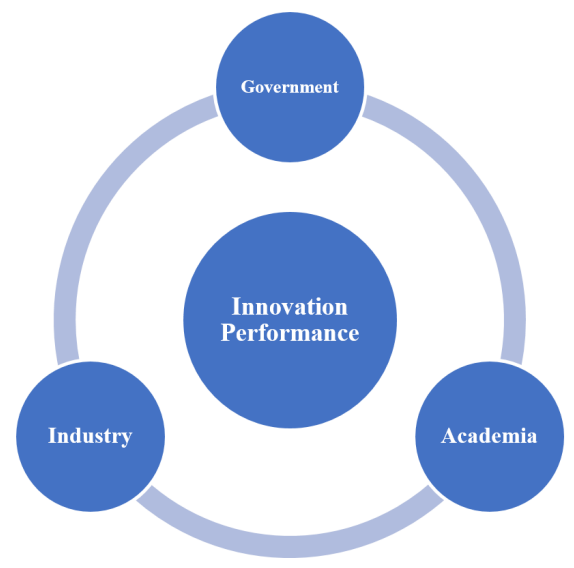

Figure 1. Dynamic model of the construction innovation system to explain various dynamic problems, policies and interactions between the system's actors, such as a government, construction companies, universities and research institutes (Figure 1).

In our study, we focus on technological innovations mainly occurring in the industry (Davis et al., 2016). They involve the utilization of technical approaches of either process or product innovation such as improvements in construction methods, improvements in efficiency and new ideas influencing functional and technological values of a standard operation (e.g. environmental features, functionality of a product), to name a few. The change in the number of innovative construction companies over time is presented in Figure 2 (FSSS, 2017).

As can be seen, the Russian government is expecting the amount of innovative construction companies to be doubled by 2020 and practically tripled by 2030 . Nevertheless, it is a very ambitious plan given the relatively short period of time and the lack of targeted strategies and rational policies. In fact, the current situation in the Russian construction industry does not show sufficient capacity enabling the achievement of such a significant growth (Suprun and Stewart, 2015). Hence, this problem motivated this research in general and the chosen

Share of construction companies, implementing technological innovations, \%

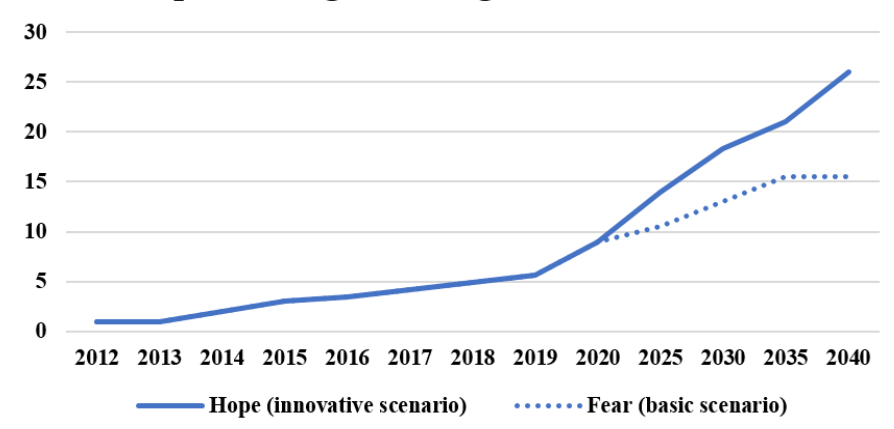

Figure 2. Behaviour over time (BOT) chart research approach is capable of exploring potential innovation outcomes resulting from a range of different innovation planning strategies and uncertain situational context scenarios which also take into account the time factor.

\section{RESEARCH APPROACH}

Given the complex nature of the construction innovation system under study, where high uncertainty and lack of data is involved, an integrated systems approach is needed as an appropriate method for modelling the multi-dimensional construction innovation process and studying the dynamic behaviour under different scenarios. A novel holistic modelling procedure (Figure 3) combines a number of various modelling methods along with qualitative expert inputs under the same framework, which is beneficial compared to traditional computer modelling approaches, taking into account the highly qualitative and complex nature of the system under study (Onyango et al., 2016; Sahin et al., 2017). Moreover, the integrated holistic modelling strategy 
aims to support the understanding of complex policy development and implementation issues due to active stakeholder engagement carried out in the following forms:

- Stakeholder identification and analysis (throughout the whole modelling process);

- Questionnaire-based survey and face-to-face interviews (problem definition stage consisting of preliminary investigation and the exploratory study);

- Consultations with academic and industry professionals (problem scoping and model conceptualisation stages);

- Opinion survey on construction innovation system (model conceptualisation applying structural analysis);

- Workshops on construction innovation performance (simulation model formulation):

- Consultation meetings with experts (model testing followed by final model simulation).

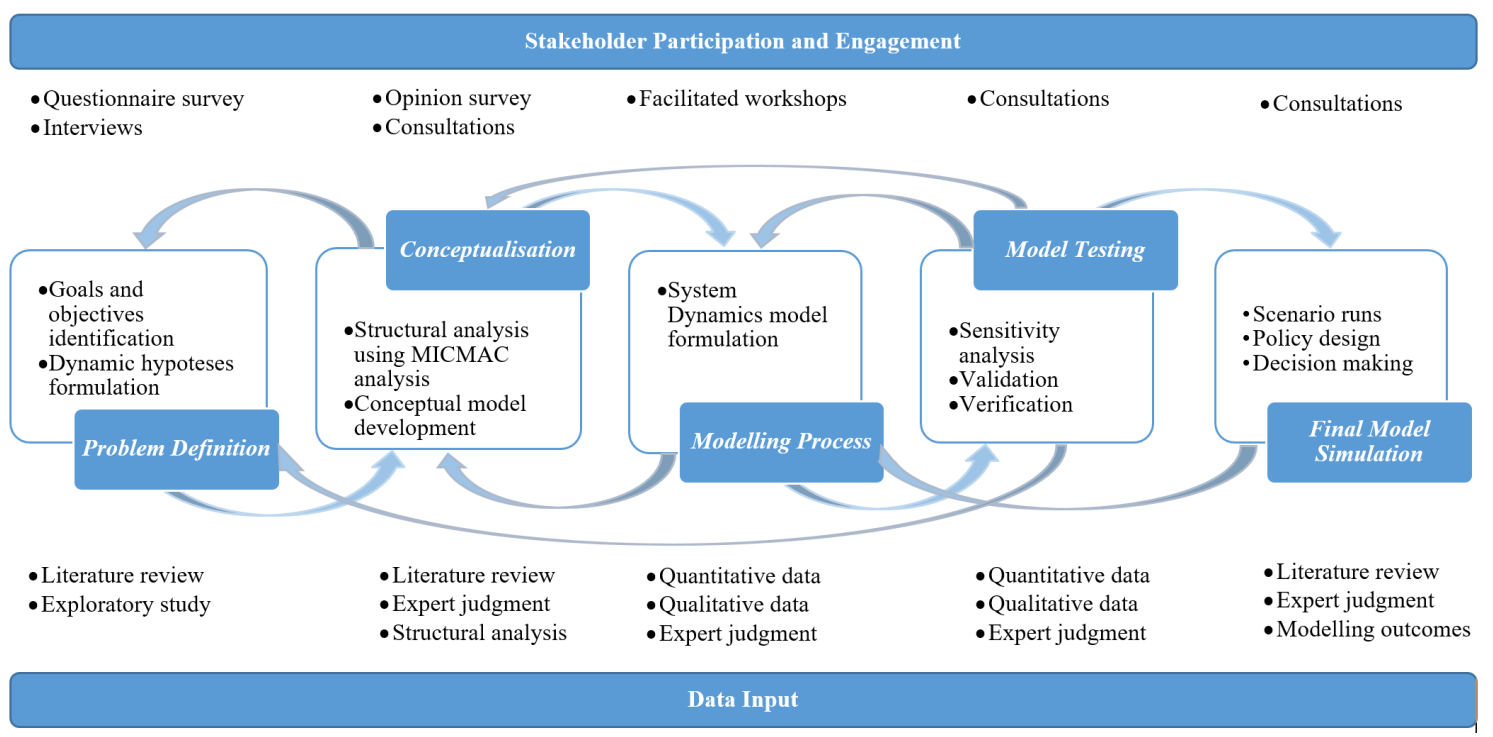

Figure 3. An integrated systems approach step-by-step modelling process

The chosen approach aims to improve the industry's innovative capabilities by analysing the interdependencies in its collaboration with academia and the government in the face of external changes in the institutional environment. The research outcomes allow decision makers to take decisions which are based on holistic, qualitative and quantitative analysis which is capable of representing highly complex and dynamic innovation-related situations in the construction industry. Moreover, the research approach can be considered as a decision support tool as it brings together the various expert views from diverse disciplines and, hence, allows them to be a part of the entire modelling process from setting the goals of the study, to the choice and discussion of policy alternatives and scenarios, generated by the relationships between government, academia and the construction industry.

In the present article, we discuss results from a conceptual model development stage followed by an initial simulation model formulation. The conceptual framework provides a higher confidence level due to a structural analysis based on the previously conducted exploratory study and active stakeholder participation and engagement.

\section{RESULTS AND DISCUSSION}

The conceptualisation modelling phase enables a deep and integrated understanding of a system under study through the qualitative exploration and classification of systemic interconnections between the system's components, considering that this process is non-linear and that the policy analysis should be done holistically. In order to build such a comprehensive conceptual model, the structural analysis procedure using MICMAC analysis was enriched (Godet, 2006; Onyango et al., 2016; Suprun et al., 2016). The main purpose of this research stage is to provide a modeller with the detailed understanding of the role of each system's element, which in turn, assists in the further simulation modelling. Moreover, the structural analysis outcomes build foundations for the further analytical integration of the system's parts which also includes complex policy analysis followed by testing of different scenarios.

To start with, the data and information regarding the interrelated variables were derived from the literature 
review by identifying generic and specific model inputs followed by a questionnaire-based survey, expert interviews and consultations (Suprun and Stewart, 2015). As a next step, the opinion survey was then conducted in order to classify the key elements and identify the relationships between them within a double input influence matrix linking all of the constitutive factors through the MICMAC ranking approach (Suprun et al., 2016). Stakeholders are experts in the construction and innovation policies area from the three groups of the system's actors such as researchers, private and public construction firms' employees and contractors, design engineers, manufacturers and representatives of public authorities. As a result, 30 key variables representing the construction innovation system's resources, activities, enablers and barriers were ranked with regard to their influences and dependencies. The variables hierarchy was established based on the following relationship evaluation: no influence (0); weak influence (1); medium influence (2); and strong influence (3). In other words, the analysis helped to quantify the strength of relationships between the system's elements in relation to the construction innovation system (Godet, 2006).

As in the main structural analysis outcomes, the direct and indirect influence graphs (Figure 4) along with influence diagrams (Figure 5) were generated using the MICMAC software (MICMAC, 2017). All the

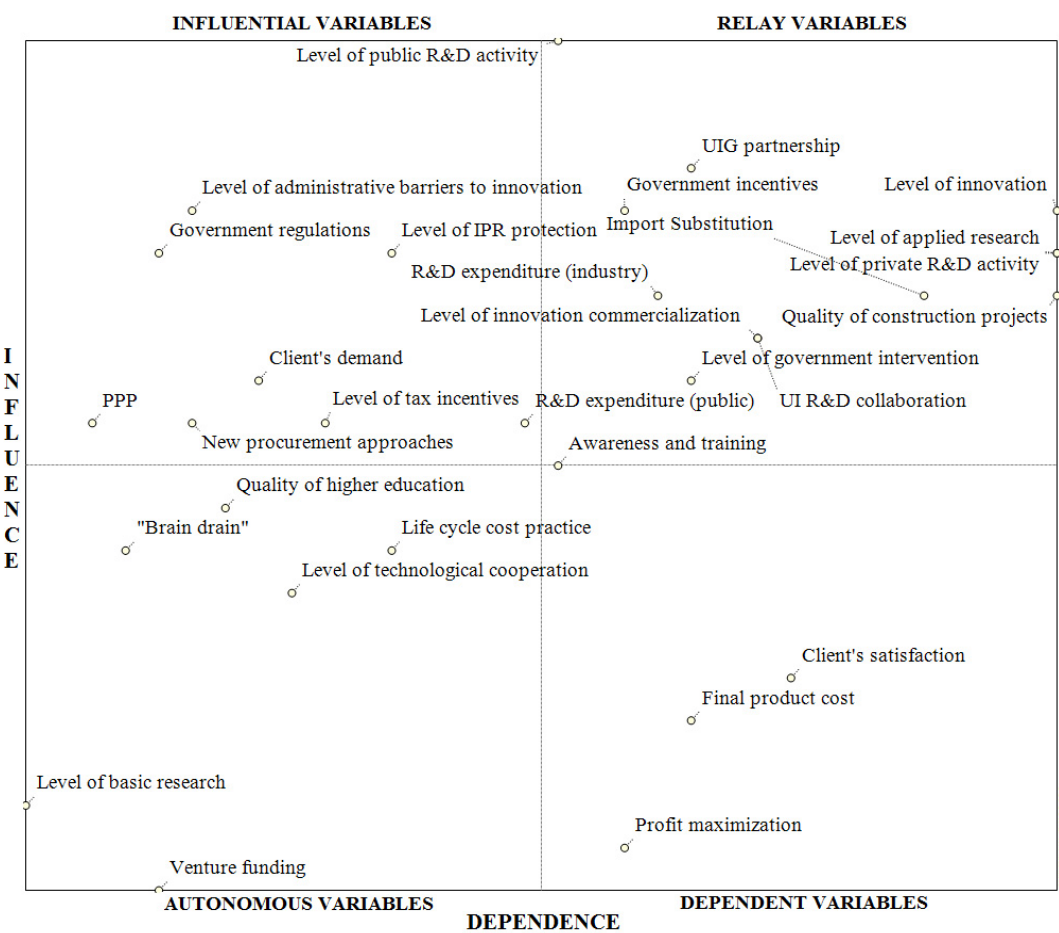

Figure 4. Direct influence and dependence map of the model variables variables were classified into the following clusters depending on the quadrant they belong to:

- Influential variables represent input variables that exert some influence on other elements and the system as a whole when they change. This group of variables is the most important for decision makers when considering policy design and, hence, must have priority and decision-making strategies.

- Relay variables impact the system and are dependent on input variables. Moreover, they are dynamic variables involved in the system's feedback loops as they have an unstable behaviour and may change to be input or output variables. In other words, they create the dynamism of the system under study. Hence, these variables are critical to the system due to their significant disruption of normal system functioning.

- Dependent variables represent the system's output variables that are most influenced by other variables and the system.

- Autonomous variables are neither influential nor dependent and are not controlled by the dynamics of the system. Hence, these variables are associated with

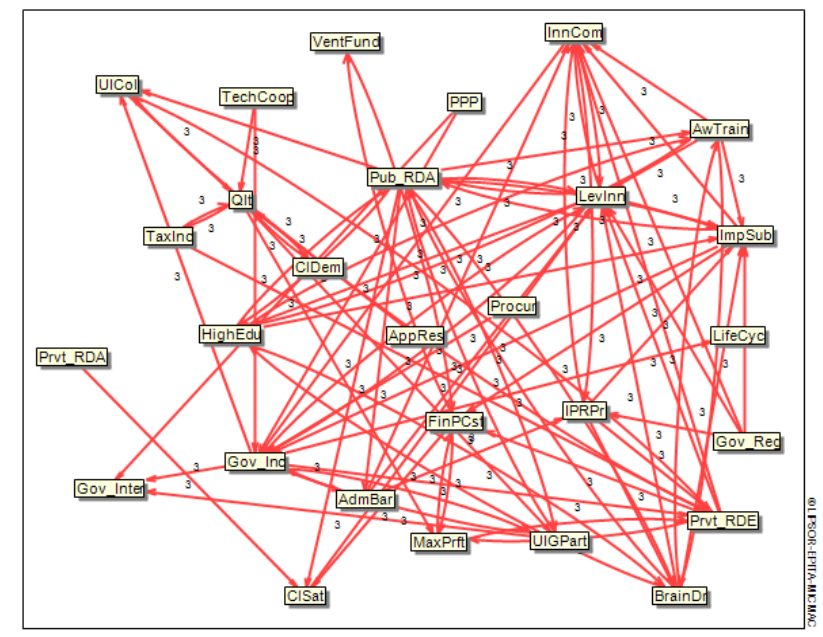

Figure 5. Direct influence graph representing 10\% of interrelations between system's variables. The arrows show the strongest influences 
exogenous components that exist within the system and, consequently, have low potential to generate changes in the system.

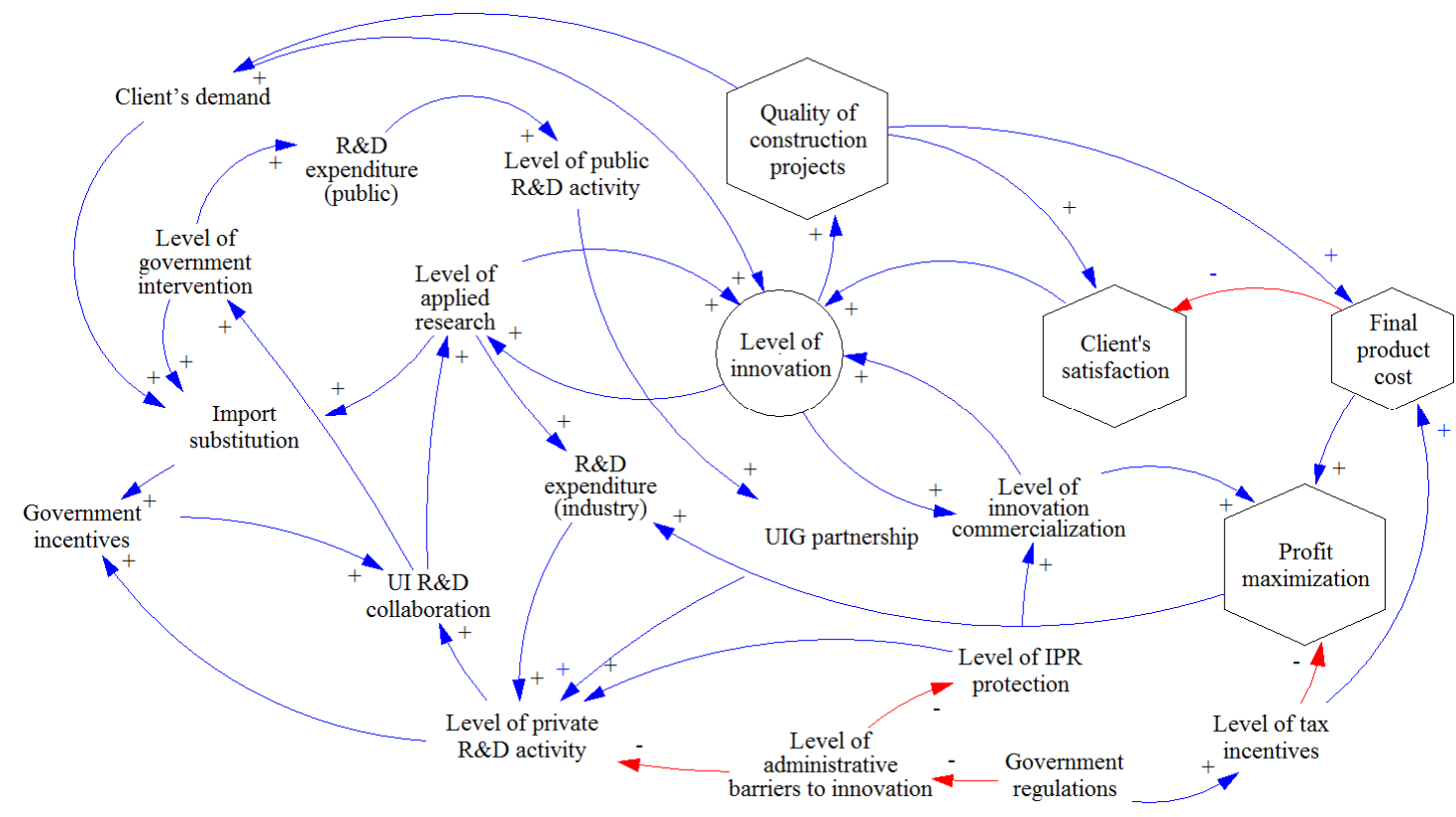

Figure 6. Conceptual model of construction innovation system based on the structural analysis. Hexagons represent construction innovation outputs. Transparent variables indicate key system's resources, activities, enablers, and the broader environment elements. The circle represents innovation performance. Blue and red arrows indicate positive $(+)$ and negative $(-)$ causal links, respectively. The polarity is ' + ' when two variables increase or decrease together. The polarity is '-' when one element increases while the other decreases, and vice versa.

As mentioned above, the interrelations among the constituent elements assist a modeller with revealing the dynamic nature of the system under study. Hence, the created structural matrix along with its graphic representation provide visual understanding of the systemic relationships between the system's components and work as a reference for generating a conceptual model in the form of an associated causal loop diagram (CLD) (Figure 6).

The generated conceptual model in its static form has multiple purposes, namely:

- to provide the foundations for further simulation modelling, exploring the dynamics of the variables relationships;

- to visually communicate the problem of construction innovation to potential stakeholders; and

- $\quad$ systematically present important scenario and policy variables associated with guidelines, formulated and enforced by decision makers (Grösser, 2017; Sterman, 2000).

It is worth noting here, the presented model has been designed as a set of elements which included drivers, enablers, strategies, activities, outputs, and so on, but not the system's actors. Consequently, the next step is to build a dynamic simulation model represented by 4 interrelated sub-models such as government, industry, academia and, innovation performance. In other words, we split the concept of the construction innovation system into different sectors to describe various activities that take place within a system in order to address the problem of the low level of construction innovation.

Following the structural analysis and conceptual model development, the second round of workshops (Table 1) was conducted, as a prelude to the exploration of construction innovation performance using system dynamics (SD) modelling. The main purpose of the workshops was to create a preliminary simulation model, implying that differences in the structuring of such complex systems create varying innovation performance. The workshops participants were experts in civil engineering, municipal and structural engineering, construction management: researchers and academics; public servants working at the construction department; cconstruction companies project managers, and; construction companies directors.

The initial after-workshops stock and flow diagrams representing four sub-models are illustrated in Figure 7. The model revels the dynamic hypotheses describing the problem under study which centres on how the 
Suprun et al., Innovation policy analysis and decision making: a systems approach

industry, academia and the government can collaborate to most effectively diffuse innovations throughout the industry. By doing so, academics and government authorities should support industrialists and encourage them to consider R\&D investments as the core of their business strategy which is especially relevant in the case of Russia and its current import substitution policy.

Table 1. Facilitated expert workshops stages overview

\begin{tabular}{|l|l|l|}
\hline Tasks & Purpose & Comments \\
\hline Introduction & Explanation of research objectives and methodology \\
\hline SD concepts & $\begin{array}{l}\text { Brief introduction of the SD language } \\
\text { (using non-technical language) }\end{array}$ & $\begin{array}{l}\text { It is necessary to introduce the stock, flow, and causal link icons to } \\
\text { be used throughout the workshop }\end{array}$ \\
\hline $\begin{array}{l}\text { System's sub- } \\
\text { models }\end{array}$ & $\begin{array}{l}\text { Discussion around the system boundary } \\
\text { and behaviour of the real system }\end{array}$ & $\begin{array}{l}\text { A preliminarily qualitative model was developed to assist } \\
\text { stakeholders with their existing understanding }\end{array}$ \\
\hline $\begin{array}{l}\text { Stocks and } \\
\text { flows }\end{array}$ & $\begin{array}{l}\text { Identification and confirmation of key } \\
\text { stock and flow structure for the system } \\
\text { under study }\end{array}$ & $\begin{array}{l}\text { The facilitator explained a basic stock and flow diagram and then } \\
\text { asked participants to identify and confirm variables that influenced } \\
\text { the rates or inflows and outflows between these stocks }\end{array}$ \\
\hline $\begin{array}{l}\text { Feedback loop } \\
\text { analysis }\end{array}$ & $\begin{array}{l}\text { Collection of feedbacks on the system's } \\
\text { components and any missing parts }\end{array}$ & $\begin{array}{l}\text { Generally, various stakeholders are experts in one part of the system, } \\
\text { hence, they take the lead when their portion of the system is under } \\
\text { discussion }\end{array}$ \\
\hline $\begin{array}{l}\text { Model } \\
\text { refinement }\end{array}$ & $\begin{array}{l}\text { Discussion around the initial qualitative } \\
\text { stock and flow model representing the } \\
\text { construction innovation system }\end{array}$ & $\begin{array}{l}\text { The model developed by participants during the workshop contained } \\
\text { the elements considered important by stakeholders and illustrated the } \\
\text { connections between them }\end{array}$ \\
\hline $\begin{array}{l}\text { Equation } \\
\text { writing and } \\
\text { parametrization }\end{array}$ & Building a formal simulation model & $\begin{array}{l}\text { This step involved presentation of some preliminary quantified parts } \\
\text { of the model. A brain-storming technique was applied to express the } \\
\text { logical relationships between the connected variables (not necessary } \\
\text { mathematically) }\end{array}$ \\
\hline $\begin{array}{l}\text { Discussion } \\
\text { potential leverage points, }\end{array}$ & $\begin{array}{l}\text { Suggestion of management strategies, } \\
\text { recommendations and scenarios }\end{array}$ & $\begin{array}{l}\text { It is very important to take into account the expert's suggestions from } \\
\text { participants representing all three groups of the system's actors } \\
\text { (industry, academia, government) }\end{array}$ \\
\hline
\end{tabular}

\section{CONCLUSIONS}

An integrated systems modelling approach was applied in this study to visualise the elements of the construction innovation system in order to reveal potential pathways to a rational decision-making process. The chosen methodology approach was deemed to be effective in building a comprehensive conceptual model along with an initial version of the simulation model. Based on the structural analysis, the construction innovation system's variables were classified into various categories. It revealed the following variables that have a priority when considering strategic policies or scenarios for the industry development: the level of

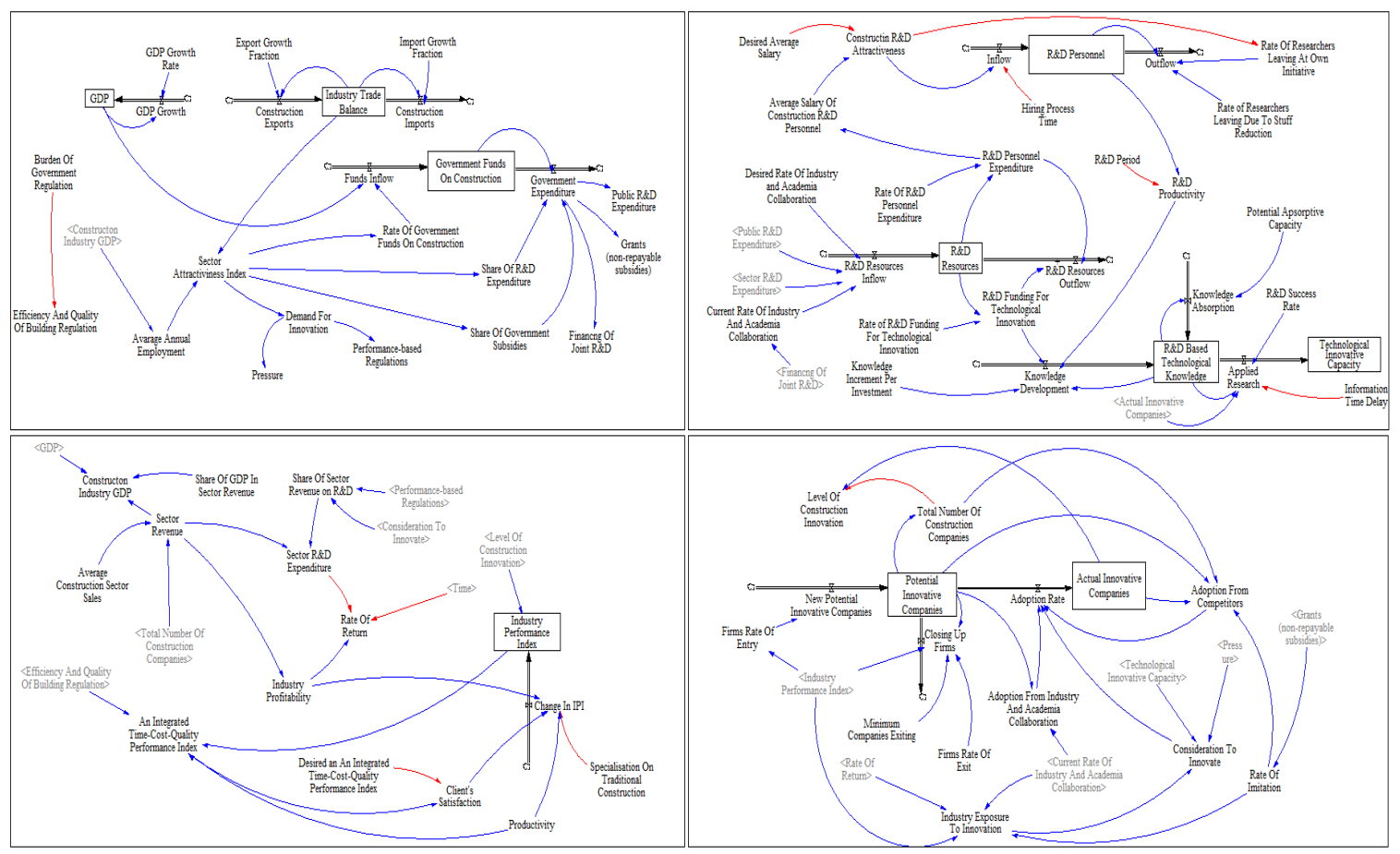

Figure 7. Stock and flow diagram in progress. 
administrative barriers to innovation, government regulations, client demand, level of public and private R\&D activity, public R\&D expenditure, import substitution, government incentives and collaboration between academia and the industry. As mentioned above, the research approach allows identification of not only the most essential variables but also how they interact. The capacity of the system's elements either to influence or to be influenced proceeds the consequences of actions related to these elements, which in-turn allow decision-makers to eliminate strategically important scenario and policy variables, associated with guidelines and recommendations in regards to construction innovation performance. In the case of the construction innovation system in Russia, it can be seen that the public sector plays a major influential role.

Further work is associated with developing a running simulation dynamic model in order to reveal potential strategic pathways to overcome innovation diffusion challenges in the Russian construction industry and encourage construction companies to innovate. Then, the verification of the model has to be tested through validation and calibration processes prior to any decision-making process (Grösser, 2017; Sterman, 2000). In fact, this step again requires an active participation of stakeholders to check if the function of the entire modelling process corresponds to real world behaviour under different scenarios.

To sum up, the overarching goal of the proposed modelling approach is to build an integrated decision making platform for the innovation sector by directly involving stakeholders in the formulation of scenarios and robust and responsive policy options. This involvement significantly improves the value of the modelling outcomes in terms of its credibility to decision makers and the community.

\section{REFERENCES}

Davis, P., Gajendran, T., Vaughan, J., and Owi, T. (2016). Assessing construction innovation: theoretical and practical perspectives. Construction Economics and Building, 16(3), 104-115.

FSSS (Russian Federation Federal State Statistics Service). (2017). Available at: www.gks.ru/ (accessed 15 June, 2017).

Godet, M. (2006). Creating Futures: Scenario Planning as a Strategic Management Tool. Économica, London.

Grösser, S.N. (2017). Complexity Management and System Dynamics Thinking. In: Dynamics of Long-Life Assets: From Technology Adaptation to Upgrading the Business Model. Springer International Publishing, Heidelberg, 66-92.

MICMAC (2017). Structural Analysis. Methods of prospective website. http://en.laprospective.fr/methodsof-prospective/softwares/59-micmac.html

Onyango, E.A., Sahin, O, Awiti, A., Chu, C., and Mackey, B. (2016). An integrated risk and vulnerability assessment framework for climate change and malaria transmission in East Africa. Malaria Journal, $15(1), 551$.

Ozorhon, B., and Kutluhan, O. (2017). Drivers of innovation in construction projects. Journal of Construction Engineering and Management, 143(4), 04016118.

Sahin, O., Bertone, E., and Beal, C. (2017). A systems approach for assessing water conservation potential through demand-based water tariffs. Journal of Cleaner Production, 148, 773-784.

Seaden, G., and Manseau, A. (2001). Public policy and construction innovation. Building Research \& Information, 29(3), 182-196.

Sterman, J. (2000). Business Dynamics: Systems Thinking and Modelling for a Complex World. Boston, MA: McGraw-Hill.

Suprun, E., Sahin, O., Stewart, R.A., and Panuwatwanich, K. (2016). Model of the Russian Federation construction innovation system: an integrated participatory systems approach. Systems, 4, 29.

Suprun, E.V., and Stewart, R.A. (2015). Construction innovation diffusion in the Russian Federation: barriers, drivers and coping strategies. Construction Innovation, 15(3), 278 - 312.

Van Egmond, E. (2012). Innovation, technology and knowledge transfer for sustainable construction. In: Construction Innovation and Process Improvement. Akintola Akintoye, Jack S. Goulding and Girma Zawdie. 1st Ed. Wiley-Blackwell, 95-123. 